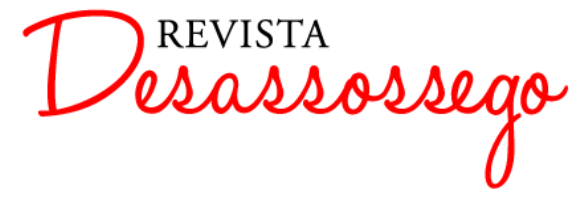

DESASSOSSEGO 12 | DEZ/2014 | ISSN 2175-3180

DOI: http://dx.doi.org/10.11606/issn.2175-3180.v6i12p120-123

\title{
Um conto de fadas português: Símbolos e Tradição em $A$ Menina do Mar, de Sophia de Mello Breyner Andresen
}

Bruno Anselmi Matangrano ${ }^{1}$

Resenha: ANDRESEN, Sophia de Mello Breyner. A Menina do Mar. Ilustrações de Veridiana Scarpelli. São Paulo: Cosac Naify, 2014, 48p.

Apesar de célebre em Portugal, a obra de Sophia de Mello Breyner Andresen (19192004) custa a ser publicada no Brasil. No meio acadêmico, evidentemente, faz parte dos cursos de graduação e pós-graduação, com presença constante nas bibliografias dos cursos de Literatura Portuguesa. Teses, dissertações e artigos vem sendo dedicados a ela e, pouco a pouco, seu nome tem se difundido do outro lado do Atlântico. Apesar disso, até há bem pouco tempo, era difícil (para não dizer praticamente impossível) encontrá-la nas livrarias brasileiras, pois afora uma coletânea chamada Poemas Escolhidos, publicada pela Companhia das Letras em 2004, ano da morte da autora, e já há muito esgotada, o público brasileiro não tinha em mãos nada da obra de Sophia, salvo quando conseguia edições portuguesas, também raras por aqui.

Em tal conjuntura, é com grande entusiasmo que seus leitores recebem $A$ Menina do Mar, livro infantil da autora, publicado originalmente em 1958, e lançado pela primeira vez no Brasil, no segundo semestre de 2014, pela editora paulista Cosac Naify.

É curioso que a única obra atualmente disponível de Sophia no mercado brasileiro seja justamente em prosa e infantil, quando ela é mais conhecida por seus poemas. Mas a escolha parece propícia, pois, a quem já está habituado com a Sophia-poeta, A Menina do Mar é, ao mesmo tempo, uma nova via de leitura e um reencontro. Uma nova via, pois, em um primeiro olhar, a atmosfera de conto de fadas parece distante de sua obra poética elaborada e erudita. Um reencontro, pois, apesar da diferença de tom, público e gênero, as imagens, cores e temas singulares e bucólicos de Sophia continuam muito presentes. Ao novo leitor é um ótimo começo. É, ao mesmo tempo, outra e a mesma Sophia, cujos olhos estão sempre voltados para o Mar e para a tensão-relação entre este e a cidade.

\footnotetext{
${ }^{1}$ Bruno Anselmi Matangrano é bacharel em Letras (português e francês) e Mestre em Literatura Portuguesa pela Universidade de São Paulo (USP). Bolsista do CNPq, atualmente, faz seu doutorado também em Literatura Portuguesa sob orientação da Profa. Dra. Annie Gisele Fernandes.
} 


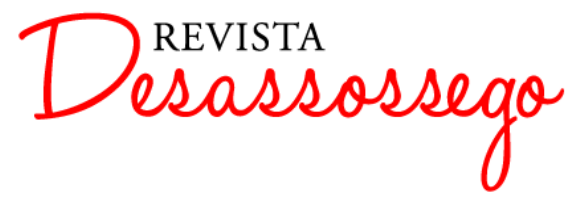

DESASSOSSEGO 12 | DEZ/2014 | ISSN 2175-3180

DOI: http://dx.doi.org/10.11606/issn.2175-3180.v6i12p120-123

A narrativa se abre com a máxima tradicional dos contos de fada: Era uma vez... e o leitor logo se descobre em uma praia tranquila às margens da qual vive um menino que gosta de brincar à beira-mar, como se lê nestas primeiras passagens: "Era uma vez uma casa branca nas dunas, voltada para o Mar" (p. 5). "Com o seu jardim de areia e flores marinhas" (p. 5).

A história se constrói da forma tradicional dos contos de fadas: ações corriqueiras que se repetem em uma rotina e que são interrompidas pelo maravilhoso todoroviano, sem que, no entanto, o elemento insólito cause estranhamento, como compete a esse gênero, segundo a tipologia proposta por Tzvetan Todorov na sua Introdução à Literatura Fantástica.

O maravilhoso se dá na forma de uma menininha, de um palmo de altura, olhos roxos e cabelos verdes que, juntamente com seus amigos - um polvo, um peixe e um caranguejo -, é encontrada pelo menino-protagonista em um de seus dias de brincadeira na praia.

O menino, então, depois de observá-la, captura-a e, a princípio, a menina o teme, pois aprendeu com os peixes que deveria sempre ter receio dos homens. O susto, no entanto, logo passa e os dois se tornam amigos. Uma nova rotina se inicia, na qual o menino passa a visitar diariamente a menina e seus amigos, levando-lhe a cada dia um presente e trocando com ela muitas histórias.

A menina revela que o seu nome é "Menina do Mar" e que não sabe como veio ao mundo ou de onde se origina. Fora criada em uma gruta por seus amigos - o polvo, o peixe e o caranguejo - e vive sob a proteção da Grande Raia, para quem dança sempre que ordenado. A Grande Raia traz em si um caráter opressor e ditador, é um monstro terrível, capaz de engolir um barco; apesar disso, gosta da Menina e de sua dança, e, por isso, não permite que nada ou ninguém lhe faça mal.

O menino, por sua vez, se encanta com aquela pequena menina e promete-lhe trazer presentes da terra. Seguindo as estruturas tradicionais dos contos de fadas, três são os presentes dados pelo menino e três cenas são descritas para apresentá-los. O primeiro presente é uma rosa, sobre qual a menina diz: "É um perfume maravilhoso. No mar não há nenhum perfume assim. Mas estou tonta e um bocadinho triste. As coisas da terra são esquisitas [...]. Na terra há tristeza nas coisas bonitas" (p. 21). Ao que o menino responde: "Isso é por causa da saudade". E quando a menina o interpela, perguntando o que é saudade, ele explica dizendo: "A saudade é a tristeza que fica em nós quando as coisas de 


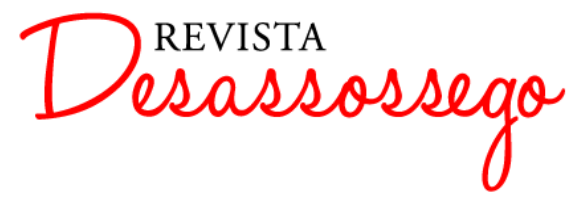

DESASSOSSEGO 12 | DEZ/2014 | ISSN 2175-3180

DOI: http://dx.doi.org/10.11606/issn.2175-3180.v6i12p120-123

que gostamos vão embora” (p. 21). Logo, o presente, ao mesmo tempo, a encanta e a entristece, ensinando-lhe assim o conceito, tão português, de saudade.

O segundo presente é um fósforo, com o qual ela aprende o que é o fogo. O fogo a encanta por sua beleza e a intriga por sua efemeridade e calor, ao que o menino explica: "O fogo é assim. Enquanto é pequeno qualquer sopro apaga. Mas depois de crescido pode devorar florestas e cidades" (p. 22). E mais adiante complementa: "Enquanto o fogo é pequeno e tem juízo é o maior amigo do homem: aquece-o no inverno, cozinha-lhe a comida, alumia-o durante a noite. Mas quando o fogo cresce de mais, zanga-se, enlouquece e fica mais ávido, mais cruel e mais perigoso de que todos os animais ferozes” (p. 24). Assim, a menina aprende a utilidade, o poder e o perigo do fogo.

O terceiro presente é o vinho que lhe dá alegria e coragem para sair do mar e ir conhecer a terra. Depois de bebê-lo, tal como o menino disse que aconteceria, a menina se sente feliz e diz: “[o vinho] É bom e alegre. Agora já sei o que é a terra. Agora já sei o que é o saber da primavera, do verão e do outono" (p. 26).

A simbologia de cada um desses três elementos merece atenção. A rosa pode simbolizar, a um só tempo, o amor, a beleza e o pecado (traz encantamento e saudade, com seu perfume e efemeridade); o fogo, também efêmero, simboliza, talvez, o conhecimento, a civilização e o poder, que com parcimônia ajuda ao homem, mas que pode levar à destruição se usado sem medida. Vale lembrar ainda, a respeito do fogo, o mito de Prometeu (o que evoca o gosto de Sophia pelos mitos gregos, evidente em quase toda a sua obra), que se sacrifica para levar o fogo - metáfora do conhecimento e da civilização - à humanidade e é punido por Zeus por tê-lo desafiado. Já o vinho pode designar a vida, o vício ou a civilização outra vez, pois, tal qual o fogo, deve ser usado com parcimônia. Além disso, é um símbolo cristão que evoca renovação e comunhão.

Tudo isso implícito em diálogos singelos e inocentes, como as passagens transcritas acima, o que lembra outras obras desta mesma tradição, como O Pequeno Príncipe, de Antoine de Saint-Exupéry (1900-1944), publicado em 1943, e O Maravilhoso Mágico de Oz, de L. Frank Baum (1856-1919), publicado em 1900, distanciando-se, portanto, da crueza dos contos de fadas tradicionais e folclóricos (vistos aqui em oposição aos contos de fadas autorais, como o de Sophia, o de Baum e o de Saint-Exupéry), como os compilados pelos irmãos Jacob (1785-1863) e Wilhelm (1786-1859) Grimm.

O final de A Menina do Mar é feliz, novamente como não poderia deixar de ser, dentro da tradição mencionada. O livro se encerra numa dança com todas as personagens, 
no fundo do mar, quase em um ritual de comunhão com a Natureza, quando então se sente a máxima não-enunciada "e viveram felizes para sempre".

Para além da história em si, vale comentar a edição da Cosac Naify, que traz ainda belas ilustrações de Veridiana Scarpelli, explorando o lado mais singelo e lúdico da obra, e ressaltando, em seus desenhos, a ligação com o mar (tão patente não apenas nessa, mas em várias outras obras de Sophia, sobretudo, em sua obra poética) ao propor uma representação da Menina do Mar com uma extensa cabeleira feita d'água, que se expande em lagoas ao longo das páginas. O traço simples evoca a infância, sem perder a beleza e a graça, em uma atmosfera leve e plácida, corroborada pelo azul que se sobressai, não apenas no desenho, como também na lombada, dessa cor tingida.

Ao fim, um glossário elucida ao leitor brasileiro algum ponto que por ventura se mantenha obscuro devido às diferenças entre o português do Brasil e o de Portugal. Uma nota da pesquisadora e professora Dra. Lilian Jacoto encerra o volume, destacando justamente o desejo de comunhão com o Mar, como se vê nesta passagem: "Em A Menina do Mar, a escritora projeta sobre crianças de todas as idades o desejo de mergulhar no Azul" (p. 45), e, por conseguinte, na Natureza, o que reflete o ideal poético otimista e panteísta, grego à sua maneira, de Sophia de Mello Breyner Andresen. 